\title{
Elevated expression of cyclooxygenase-2 is a negative prognostic factor for overall survival in intrahepatic cholangiocarcinoma
}

\author{
Klaus Jürgen Schmitz • Hauke Lang • \\ Jeremias Wohlschlaeger • Henning Reis • \\ Georgios Charalambos Sotiropoulos • \\ Kurt Werner Schmid • Hideo Andreas Baba
}

Received: 17 August 2006 /Revised: 17 October 2006 / Accepted: 19 November 2006 / Published online: 13 December 2006

(C) Springer-Verlag 2006

\begin{abstract}
The production of prostaglandins is regulated by cyclooxygenases (COXs), which also have a role in tumour development and progression in various human malignancies, including cholangiocarcinoma. Limited information is available of the correlation of COX-2 protein expression and prognosis in intrahepatic cholangiocarcinoma (ICC). The aim of the present study was to determine the clinical significance of COX-2 expression in ICC. In addition the correlation of COX-2 expression and apoptosis/proliferation was analysed. COX-2 expression was determined immunohistochemically in 62 resected ICCs. Proliferation was assessed using Ki67-immunohistochemistry, and apoptosis was measured with the TdT-mediated dUTP nickend-labelling technique. COX-2 was identified as an independent prognostic factor $(P=0.028)$ in resected ICC by survival analysis. High levels of COX-2 expression were found to be associated both with reduced apoptosis and increased proliferation of tumour cells. This study demonstrates the independent prognostic value of the COX-2 expression in resected ICC, thus, offering a potential
\end{abstract}

K. J. Schmitz $\cdot$ J. Wohlschlaeger $\cdot$ H. Reis $\cdot$ K. W. Schmid $\cdot$

H. A. Baba $(\square)$

Institute of Pathology and Neuropathology,

University Hospital of Essen, University of Duisburg-Essen,

Hufelandstr. 55,

45147 Essen, Germany

e-mail: hideo.baba@uk-essen.de

H. Lang $\cdot$ G. C. Sotiropoulos

Department of General, Visceral and Transplantation Surgery, University Hospital of Essen, University of Duisburg-Essen,

Essen, Germany

H. Lang $\cdot$ K. W. Schmid

West German Cancer Centre Essen (WTZE),

Essen, Germany additional adjuvant therapeutic approach with COX-2 inhibitors.

Keywords Cancer $\cdot$ Mol path $\cdot$ Immunohistochem

\section{Introduction}

Cholangiocarcinoma (CCC) is composed of cells resembling those of bile ducts. CCC arises either from the extrahepatic duct including the hilar bifurcation or from the intrahepatic ducts. Intrahepatic cholangiocarcinoma (ICC) is less frequent than extrahepatic bile duct carcinoma but second among primary malignant liver tumours after hepatocellular carcinoma. In Western countries, ICC accounts for about $10 \%$ of the primary liver malignancies with increasing incidence in the last two decades [24]. The identification of patients with most aggressive ICC might help to optimise surgical treatment and avoid unnecessary surgical therapy. Therefore, it is desirable to identify molecular markers that individually predict tumour behaviour and may facilitate an individualized therapy.

Among the potential prognostic parameters, cyclooxygenase (COX)-2 is of particular interest, as it may also offer the option of treatment with nonsteroidal anti-inflammatory drugs (NSAIDs) [15]. COXs regulate the synthesis of prostaglandins and are, thus, the major target of NSAIDs. Its two isoforms (COX-1 and COX-2) have different expression patterns, with COX-1 being expressed in a broad variety of tissues. COX-2 has been shown to participate in tumour development and progression [11, 21]. Both elevated COX-2 messenger RNA (mRNA) and protein levels were found to be raised in ICC $[3,9]$. There exist only few studies dealing with the potential prognostic 
value of the COX-2 expression. A small study with only 24 cases of CCC could not prove a significant association with survival; however, this study did not discriminate between extra- and intrahepatic cholangiocarcinoma [12]. Another study on extrahepatic cholangiocarcinoma failed to demonstrate a correlation of the COX-2 expression and the patients' outcome in CCC [16]. In the present study, COX2 expression was determined by immunohistochemistry in one of the largest contemporary series of consecutive resected ICC. The findings were correlated with a broad range of clinicopathological features. Recent observations suggest that COX-2 overexpression may cause a prostaglandin E2-mediated inhibition of apoptosis in CCC. Moreover, COX-2 overexpression was shown to increase cell growth by the activation of $\mathrm{E}$ series of prostaglandins (EP receptors) [8, 31]. Thus, apoptosis and proliferation was determined in this series to monitor a putative imbalance between cell death and cell proliferation induced by COX-2 protein overexpression [26].

\section{Materials and methods}

Between August 1998 and August 2006, a total of 62 patients with a mean age of $58 \pm 11.5$ years were available for this study. The study comprised consecutive patients who underwent surgery for liver resection. Patients solely undergoing an explorative laparatomy without subsequent resection were excluded from the study. Patients with hilar cholangiocarcinoma, gallbladder carcinoma, or mixed hepato/-CCC and liver cirrhosis were also excluded from the study. The diagnosis of ICC was based on histology by the examination of the resected liver specimen. The tumours were classified according to the pathologic TNM (pTNM) system (sixth edition) [28]. Detailed clinical data was available including preoperative therapy, operative details, and pathological findings including surgical radicability, tumour staging, and clinical follow-up. One patient suffered from primary sclerosing cholangitis without cirrhosis; hepatolithiasis was not present in any case. Data were completed by August 2006, and minimum follow-up was every six months or until death. The median length of the follow-up was 12 months.

Immunohistochemistry

Immunohistochemistry was performed with an automated staining device (Dako Autostainer, Glostrup, Denmark).

\section{Cyclooxygenase-2}

In this study, a monoclonal rabbit anti-human COX-2 antibody (DCS, Hamburg, Germany) was used. Immuno- histochemistry was performed on 5 - $\mu \mathrm{m}$-thick paraffin, and antigen retrieval was carried out with $0.01-\mathrm{M}$ citrate buffer at $\mathrm{pH} 6.1$ for $20 \mathrm{~min}$ in a hot water bath $\left(95^{\circ} \mathrm{C}\right)$. The primary antibody was incubated for $30 \mathrm{~min}$ at 1:250 dilution. Antibody demonstration was achieved using the commercially available anti-mouse IgG detection kit (EnVision, DakoCytomation, Carpenteria, CA, USA) The replacement of the primary antibodies by mouse immunoglobin served as negative controls. Positive controls (colorectal carcinoma) were included in each staining series. In ICC, COX-2 was scored according to the amount of positive stained tumour cells. One complete tumour slide was examined for specific cytoplasmic COX-2 immunostaining. If none or less than $10 \%$ of the tumour cells showed specific COX-2 immunostaining regardless of staining intensity, the case was classified as negative. The cases with $11-50 \%$ of the positively stained tumour cells were classified as moderately positive and tumours with more than $50 \%$ stained tumour cells as strongly positive.

Ki67 immunostaining and TdT-mediated dUTP nick-end labelling

Ki67 immunohistochemistry was performed on 5- $\mu$ m-thick paraffin sections. Dewaxed and rehydrated sections were incubated with hydrogen peroxide to block endogenous peroxidase. After the antigen retrieval in a hot water bath, the prediluted monoclonal anti-Ki67 antibody (Biogenex, San Ramon, USA) was incubated for 30 min; antibody demonstration was performed with the commercially available anti-mouse IgG detection kit (EnVision, DakoCytomation). The replacement of the primary antibodies by mouse immunoglobin served as negative controls.

The growth fraction was defined as the percentage of Ki67-positive, randomly chosen nuclei per 600 tumour cells. In situ DNA fragmentation was established using the terminal desoxyribonucleotide transferase TdT-mediated dUTP nick-end-labelling technique (TUNEL) in paraffinembedded sections. We used ApoTag ${ }^{\mathrm{TM}}$ plus peroxidase in situ apoptosis detection kit (Intergen). The staining procedures were performed according the manufacturer's recommendations. The percentage of the stained apoptotic tumour cells per 600 randomly chosen tumour cells was calculated. To avoid miscounting of the necrotic cells, corresponding $\mathrm{H} \& \mathrm{E}$ sections were examined.

Statistical analysis

COX-2 immunostaining was assessed by two of the authors (K.J.S., H.R.) in a blind-trial fashion without knowledge of the clinical outcome. In case of disagreement, slides were re-evaluated by both investigators until agreement was reached. All data were converted to a PC and statistically 
Fig. 1 Immunostaining for COX-2 in noncancerous intrahepatic bile duct epithelial cells. Whereas portal bile ducts distant from the ICC consistently lacked COX-2 immunostaining (asterisk, left side), bile duct epithelial cells (asterisk, right side) adjacent to ICC (arrow) exhibited cytoplasmic immunoreactivity of varying intensity. Notice the COX-2 protein expression in normal hepatocytes. Original magnification, $\times 400$
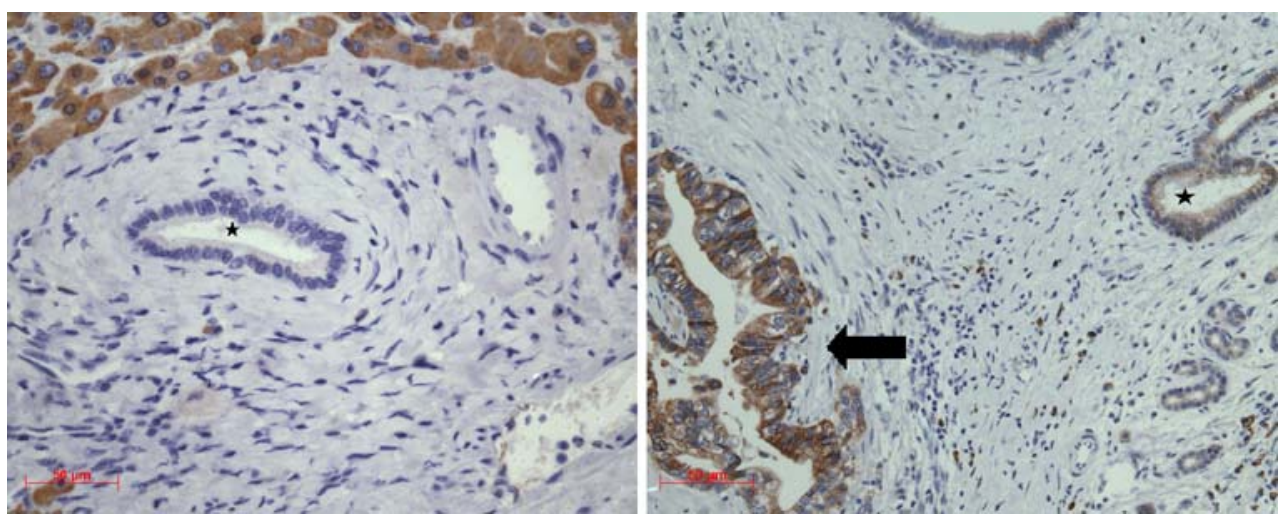

analysed using SPSS version 12 for Windows Statistical Package for Social Sciences, Chicago, IL, USA.

The kappa coefficient of the inter-observer agreement was calculated for the semiquantitative COX-2 immunostaining results; the interpretation of the kappa value was performed using the commonly cited scale of Landis and Koch [19]. The interobserver agreement of COX-2 immunostaining was substantial (kappa $=0.73$ ). Relationships between ordinal parameters were investigated using the two-tailed $\chi^{2}$ analysis (or the Fisher's exact test where patient numbers were small). The relationship between categorical data (e.g. COX2) and numeric data (e.g. number on $\mathrm{Ki}-67$ positive tumour cells) was determined using the ANOVA test. The overall survival (OS) curves were estimated using the Kaplan-Meier method, and any differences in the survival curves were compared by the log-rank test. For multivariate analysis, the COX regression model was used. Overall, 95\% confidence intervals were used throughout.

\section{Results}

\section{COX-2 immunohistochemistry}

The COX-2 immunostaining was located in the cytoplasm of epithelial cells. The plasma cells exhibited a positive cytoplasmic immunostaining, serving as internal control.
Noncancerous intrahepatic bile duct epithelial cells next to invasive cancer showed frequently a positive COX-2 immunoreactivity, whereas no COX-2 staining could be detected distant from the tumour (Fig. 1). Hepatocytes near and distant from ICC revealed a positive staining in all cases. In all, $12(19.4 \%)$ tumours were classified as negative, $25(40.3 \%)$ as moderately positive, and 25 $(40.3 \%)$ as strongly positive. Epithelial tumour cells exhibited a broad range of COX-2 immunoreactivity with a complete lack of staining or a specific and strong granular cytoplasmic COX-2 immunostaining (Fig. 2). COX-2 staining was not associated with any of the investigated clinicopathological parameters (Table 1).

\section{Clinical outcome by COX-2 expression}

OS dependent on COX-2 expression was analysed using Kaplan-Meier survival ( $n=62 ; p=0.036$; Fig. 3 ). Patients with a strong COX-2 expression exhibited a significantly decreased OS, whereas patients classified as COX-2 negative revealed the most favourable OS. The unfavourable prognostic effect of tumours with elevated COX-2 protein expression remained in the subgroup of patients with primarily R0-resected ICC $(n=39 ; p=0.038)$.

The parallel univariate survival analysis showed a significant association of the resection status $(p<0.001)$, multifocal tumour growth $(p=0.005)$, higher International Union

Fig. 2 Representative COX-2 immunostaining results in ICC. Missing COX-2 staining (left) in contrast to strong cytoplasmic COX-2 immunoreactivity in ICC tumour cells (right). Original magnification, $400 \times$. Inset: positive control (colorectal carcinoma) with strong immunostaining
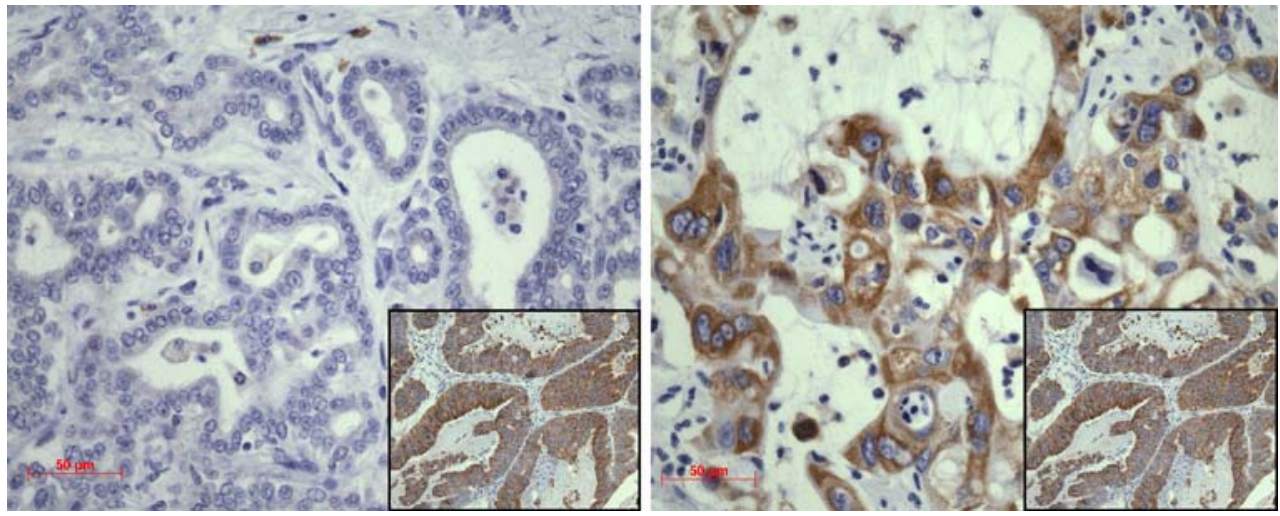
Table 1 COX-2 expression, demographic characteristics, and clinicopathological characteristics in 62 patients of the resected ICC

\begin{tabular}{|c|c|c|c|c|c|}
\hline & All & COX-2 negative & COX-2 moderate & COX-2 strong & $P$ values \\
\hline$n(\%)$ & 62 & $12(19.4)$ & $25(40.3)$ & $25(40.3)$ & \\
\hline Gender (male/female) & & $7 / 5$ & $9 / 16$ & $10 / 15$ & 0.422 \\
\hline Mean age at diagnosis $(y \pm \mathrm{SD})$ & $58.8 \pm 11.5$ & $52 \pm 12.1$ & $60.4 \pm 9.8$ & $60.6 \pm 11.8$ & 0.067 \\
\hline Grading & & & & & 0.612 \\
\hline $\mathrm{G} 1(n \%)$ & $2(3.2)$ & $0(0)$ & $2(100)$ & $0(0)$ & \\
\hline $\mathrm{G} 2(n \%)$ & $41(66.1)$ & $7(17.1)$ & $15(36.6)$ & $19(46.3)$ & \\
\hline G3 $(n \%)$ & $19(30.6)$ & $5(26.3)$ & $8(42.1)$ & $6(31.6)$ & \\
\hline UICC stage grouping & & & & & 0.277 \\
\hline I & 16 & $6(37.5)$ & $3(18.8)$ & $7(43.8)$ & \\
\hline II & 3 & $0(0)$ & $1(33.3)$ & $2(66.7)$ & \\
\hline IIIA,B,C & 38 & $5(13.2)$ & $19(50)$ & $14(36.8)$ & \\
\hline IV & 5 & $1(20)$ & $2(40)$ & $2(40)$ & \\
\hline Staging & & & & & 0.390 \\
\hline $\mathrm{T} 1(\mathrm{n}, \%)$ & 21 & $7(33.3)$ & $5(23.8)$ & $9(42.9)$ & \\
\hline $\mathrm{T} 2(\mathrm{n}, \%)$ & 7 & $0(0)$ & $4(57.1)$ & $3(42.9)$ & \\
\hline $\mathrm{T} 3(\mathrm{n}, \%)$ & 28 & $4(14.3)$ & $13(46.4)$ & $11(39.3)$ & \\
\hline $\mathrm{T} 4(\mathrm{n}, \%)$ & 6 & $1(16.7)$ & $3(50)$ & $2(33.3)$ & \\
\hline Lymph vessel infiltration & & & & & 0.121 \\
\hline Lo & 47 & $7(14.7)$ & $18(38.3)$ & $22(46.8)$ & \\
\hline L1 & 15 & $5(33.3)$ & $7(46.7)$ & $3(20)$ & \\
\hline Blood vessel infiltration & & & & & 0.916 \\
\hline V0 & 39 & $8(20.5)$ & $15(38.5)$ & $16(41)$ & \\
\hline V1 & 23 & $4(17.4)$ & $10(43.5)$ & $9(39.1)$ & \\
\hline Nodal status ${ }^{\mathrm{a}}$ & & & & & 0.281 \\
\hline 0 & 37 & $10(27)$ & $15(40.5)$ & $12(32.4)$ & \\
\hline 1 & 21 & $2(9.5)$ & $10(47.6)$ & $9(42.9)$ & \\
\hline Distant metastasis & & & & & 0.999 \\
\hline No & 57 & $11(19.3)$ & $23(40.4)$ & $23(40.4)$ & \\
\hline Yes & 5 & $1(20)$ & $2(40)$ & $2(40)$ & \\
\hline Solitary tumour ${ }^{\mathrm{b}}$ & 32 & $7(21.9)$ & $11(34.4)$ & $14(43.8)$ & 0.545 \\
\hline Multifocal tumour & 29 & $5(17.2)$ & $14(48.3)$ & $10(34.5)$ & \\
\hline Tumour size & 8.1 & $8.75 \pm 4.3$ & $8.3 \pm 2.9$ & $7.4 \pm 3.6$ & 0.506 \\
\hline Resection status & & & & & 0.627 \\
\hline $\mathrm{R} 0$ & 39 & $9(32.1)$ & $15(38.5)$ & $15(38.5)$ & \\
\hline $\mathrm{R} 1 / 2^{\mathrm{c}}$ & 23 & $3(13)$ & $10(43.5)$ & $10(43.5)$ & \\
\hline
\end{tabular}

$P$ values were calculated using chi-square analysis and ANOVA for continuous variables

${ }^{a}$ Data available for 58 patients; ${ }^{\mathrm{b}}$ data available for 61 patients; ${ }^{\mathrm{c}} 20$ cases were classified R1, only 3 were R2

Against Cancer (UICC) stage $(p=0.012)$, and vascular invasion $(p=0.011)$ with a reduced OS. Table 2 shows the mean OS for all patients in the various subgroups.

To clarify the independent prognostic value of the COX2 expression in the patients with resected ICC, a multivariate analysis of the relevant parameters was performed. The $\mathrm{COX}$ regression analysis revealed the R-classification to be the best prognostic factor for OS followed by the COX-2 expression (Table 3).

\section{COX-2 and apoptosis/proliferation}

There were significant lower mean numbers of apoptotic tumour cells per 600 tumour nuclei in tumours with strong COX-2 expression in contrast to tumours with moderate or negative COX-2 immunoreactivity (Table 4). In contrast, the proliferative activity increased in tumours with high levels of COX-2, reflected by a higher mean value of proliferating tumour cells. However, due to a substantial overlap of values, statistical significance was not reached.

\section{Discussion}

CCC is a devastating cancer of the hepatic biliary tract. The assessment of the individual prognosis of ICC patients may be helpful to optimise decision making for surgical treatment and avoid unnecessary surgical therapy. At present, surgical therapy remains the only curative treatment for ICC; thus, novel therapeutic strategies for this aggressive cancer are necessary. This study on a large series of 62 patients with resected ICC showed the independent 
Fig. 3 Kaplan-Meier survival curves in resected intrahepatic cholangiocarcinoma in relation to different COX-2 expression. Tumours with elevated COX-2 levels exhibit a significantly decreased overall survival ( $p=$ 0.036, Log Rank test)

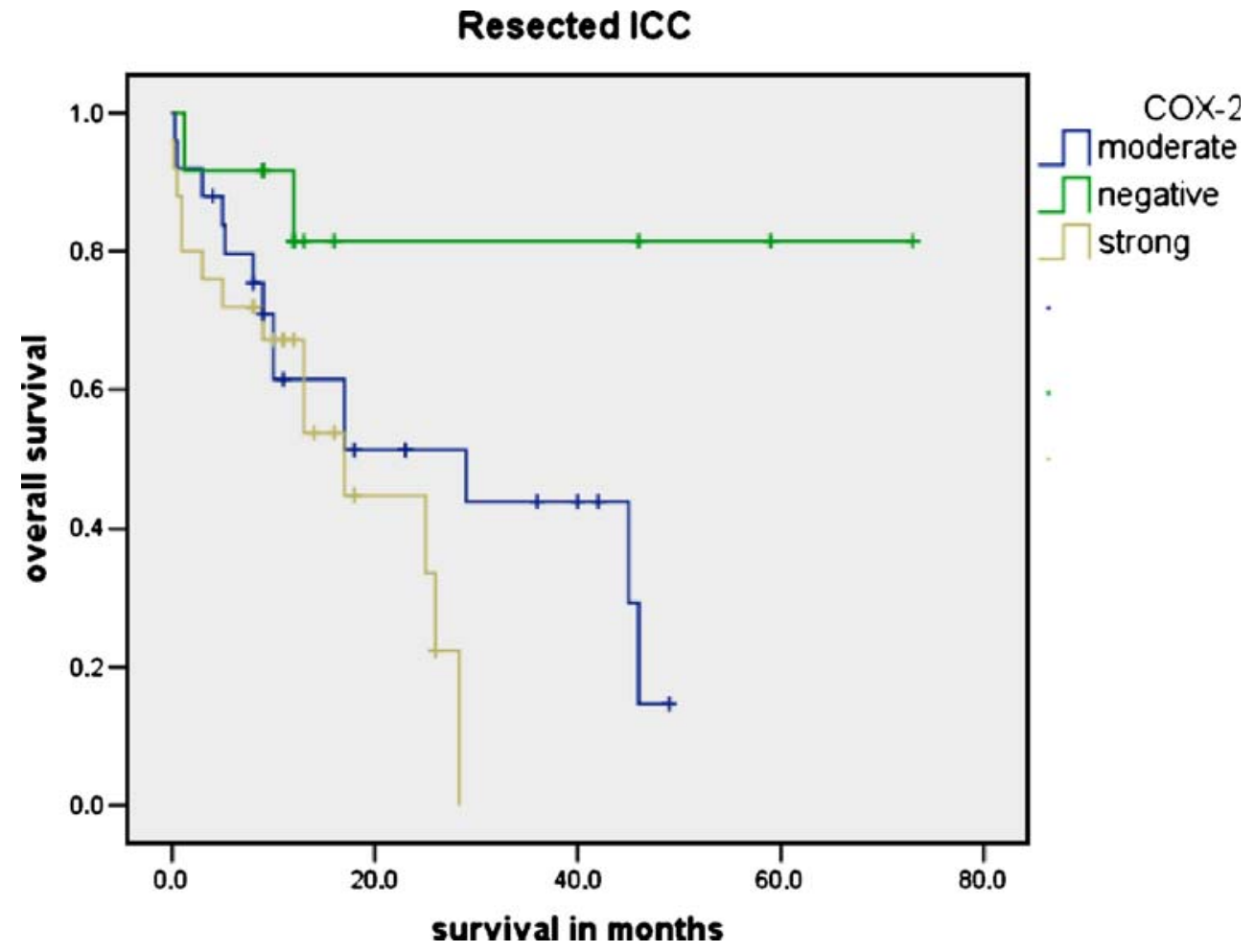

inactivation of tumour-suppressor genes [1]. Because cell line studies suggest COX-2 both as an effector and inhibitor of the tumour suppressor p53 or DNA-damaging agents [4, 7], different genetic patterns in ICC and BDC, with varying induction of COX-2 gene/protein expression, might explain the diverse clinical impact of COX-2 in ICC and BDC.

A small study on 24 patients with CCC failed to show a prognostic significance of the COX-2 expression [12]. However, the power of this study is limited due to two reasons: (1) The authors did not discriminate between extraand intrahepatic cholangiocarcinoma, and (2) the statistical power of a small series with 24 patients is very low. However, Javle et al. [12] demonstrated in their study that the median survival time of patients with low COX-2 expression was more than twice as high than that of patients with high COX-2 expression. This finding is in accordance with our results identifying COX-2 overexpression as a predictor of reduced OS. Javle et al. found COX-2 to be

Table 3 Multivariate COX regression analysis for overall survival in 62 patients with resected intrahepatic cholangiocarcinoma

\begin{tabular}{llc}
\hline & HR $(95 \%$ CI $)$ & $P$ values \\
\hline pTstage I-II/III-IV & $1.63(0.44-6.02)$ & 0.465 \\
UICC I-II, III-IV & $1.20(0.62-2.35)$ & 0.589 \\
Multifocality, solitary/multifocal & $1.26(0.41-3.89)$ & 0.689 \\
Resection status, R0/R1, R2 $^{\mathrm{a}}$ & $3.08(1.27-7.44)$ & 0.012 \\
Vascular invasion, V0/V1 $_{\text {COX-2, negative/moderate/strong }}$ & $1.98(0.88-4.41)$ & 0.095 \\
& $1.07(1.07-3.49)$ & 0.028
\end{tabular}

${ }^{\mathrm{a}}$ Twenty cases were classified R1, only three were R2 
Table 4 Apoptosis (TUNEL) and proliferative activity (Ki67) in relation to COX-2 expression

\begin{tabular}{lllll}
\hline & $\begin{array}{l}\text { All (mean } \\
\text { value/SD) }\end{array}$ & $\begin{array}{l}\text { COX-2 } \\
\text { negative }\end{array}$ & $\begin{array}{l}\text { COX-2 } \\
\text { moderate/ } \\
\text { strong }\end{array}$ & $\begin{array}{l}P \\
\text { values }\end{array}$ \\
\hline $\begin{array}{l}\text { Apoptosis } \\
\text { (percentage of } \\
\text { positive tumour } \\
\text { cells) }\end{array}$ & $2.17 \pm 2.40$ & $3.84 \pm 4.04$ & $1.76 \pm 1.73$ & 0.028 \\
$\begin{array}{l}\text { Growth fraction } \\
\text { (percentage of }\end{array}$ & $9.74 \pm 7.37$ & $8.55 \pm 8.41$ & $9.99 \pm 7.34$ & 0.486 \\
$\begin{array}{l}\text { Ki67 positive } \\
\text { tumour cells) }\end{array}$ & & & & \\
\hline
\end{tabular}

$P$ values were calculated using ANOVA for continuous variables

expressed in all 24 ICC, whereas in our study, only $81 \%$ of ICC exhibited an either moderate or strong COX-2 expression. Kim et al. [16] found COX-2 to be overexpressed in only $52 \%$ of the examined extrahepatic cholangiocarcinomas. These discrepancies are likely to be caused by differences in antigen retrieval and varying scoring systems, emphasizing the relevance of standardized protocols and immunoscores.

Previous studies suggest COX-2 overexpression as an early carcinogenetic event in the human biliary tract and pointed out that COX-2 expression was highest in more differentiated CCC, whereas COX-2 expression decreased with the loss of differentiation [5]. Our study did not reveal a significantly increased COX-2 expression in tumours with higher differentiation. Nevertheless, a detailed analysis of our data rather supports this notion. The group of well and moderately differentiated tumours exhibited the highest amount of cancers classified as strongly COX-2 positive $(44.2 \%)$ in contrast to ICC with poor tumour differentiation $(31.6 \%)$. On the other hand, we found the lowest levels of COX-2 expression to be more frequent in poorly differentiated tumours $(26.3 \%)$ in contrast to well or moderately differentiated ICC (16.5\%). The study by Kim et al. [16] on 102 extrahepatic cholangiocarcinoma describes no significant differences in terms of tumour differentiation. In the light of these varying data, one should be careful not to draw premature conclusions about the differential expression COX-2 protein in ICC.

The clinical conditions associated with ICC include parasitic liver fluke infestations, hepatolithiasis, which is frequently observed in clonorchiasis [10], nonbiliary cirrhosis, and primary sclerosing cholangitis [30]. It would be interesting to compare the levels of COX-2 expression in ICC with or without these established associated clinical risk factors. However, our series is not suitable to answer this question because all cases with liver cirrhosis, regardless of its origin, were excluded from our study to maintain the high homogeneity of our cohort and rule out cirrhosis- related influence on patient survival. As a consequence, this series comprises only one patient with associated primary sclerosing cholangitis. Patients with liver fluke infestations and associated hepatolithiasis were not present in this series because our cohort is composed from patients living in western Europe.

Interestingly, we found the up-regulation of $\mathrm{COX}-2$ protein expression not only in cancerous epithelial cells but also in noncancerous epithelial cells adjacent to invasive cancer. Noncancerous epithelial cells distant from the ICC lacked COX-2 immunostaining. This staining pattern is in accordance with the results of Hayashi et al. [9]. The elevated expression of COX-2 in bile duct epithelial cells adjacent to invasive cancer is not surprising, as inflammation often accompanies invasive cancer and inflammatory cytokines such as IL-1 $\alpha$ [22], IL-1 $\beta$ [2], or TNF- $\alpha$ are believed to induce COX-2 gene at the transcriptional level [23]. We observed a constant positive specific immunostaining in normal hepatocytes regardless of the distance to the ICC. This finding is in agreement with previous studies documenting elevated COX-2 protein and mRNA expression in nontumourous liver [3, 17].

Against the background of NSAIDs, recent studies have evaluated selective COX- inhibitors for their effect on CCC cells cell growth and invasion in vitro and in nude mice $[6,18$, $27,32,33]$. The treatment with COX-2 inhibitors resulted in induced apoptosis and inhibited proliferation. The mechanisms by which COX-2 contributes to the poor prognosis in variety of human cancers have not been completely elucidated yet. COX-2 has been shown to contribute to both tumourigenesis and the malignant phenotype of tumour cells by different mechanisms, including (1) the inhibition of apoptosis by the activation of the PI3-Kinase/Akt pathway and increased production of PGE2, leading to increased expression of Bcl-2 and attenuation of nitric oxide signalling, (2) increased angiogenesis by increased PGE2 production with subsequent vascular endothelial growth factor production, (3) increased invasiveness by the overexpression of CD44, and (4) increased cell growth by the activation of EP receptors $[8,31]$. The above mentioned effect of COX-2 overexpression on apoptosis and proliferation can be confirmed in our study. COX-2 over-expressing ICC revealed a significantly decreased apoptosis and a higher mean value of proliferating tumour cells, although the latter finding did not reach statistical significance. This finding suggests an impaired balance between cell loss and cell gain, resulting in a shift towards tumour net tumour growth due to increased apoptosis. The observed decrease of apoptosis in COX-2 overexpressing ICC might be due to the PGE2mediated induction of the antiapoptotic protein $\mathrm{Bcl}-2$ and increased NFKB transcriptional activity, which is a key antiapoptotic mediator $[25,26]$.

In conclusion, this study demonstrates the independent prognostic value of immunohistochemical COX-2 protein 
expression in resected ICC, thus, offering a potential additional adjuvant therapeutic approach with COX-2 inhibitors and facilitating an optimised therapeutic strategy. Our results suggest that COX-2 overexpression causes a shift towards increased tumour cell proliferation and decreased apoptosis contributing to the unfavourable clinical course.

Acknowledgement The technical assistance of Dorothe Möllmann, Gabi Ladwig, Renate Kern, and Nicole Cramer und Karin Scholz is gratefully acknowledged.

\section{References}

1. Argani P, Shaukat A, Kaushal M, Wilentz RE, Su GH, Sohn TA, Yeo CJ, Cameron JL, Kern SE, Hruban RH (2001) Differing rates of loss of DPC4 expression and of p53 overexpression among carcinomas of the proximal and distal bile ducts. Cancer 91:1332-1341

2. Belvisi MG, Saunders MA, Haddad E, Hirst SJ, Yacoub MH, Barnes PJ, Mitchell JA (1997) Induction of cyclo-oxygenase-2 by cytokines in human cultured airway smooth muscle cells: novel inflammatory role of this cell type. Br J Pharmacol 120:910-916

3. Chariyalertsak S, Sirikulchayanonta V, Mayer D, Kopp-Schneider A, Furstenberger G, Marks F, Muller-Decker K (2001) Aberrant cyclooxygenase isozyme expression in human intrahepatic cholangiocarcinoma. Gut 48:80-86

4. Choi EM, Heo JI, Oh JY, Kim YM, Ha KS, Kim JI, Han JA (2005) COX-2 regulates p53 activity and inhibits DNA damage-induced apoptosis. Biochem Biophys Res Commun 328:1107-1112

5. Endo K, Yoon BI, Pairojkul C, Demetris AJ, Sirica AE (2002) ERBB2 overexpression and cyclooxygenase-2 up-regulation in human cholangiocarcinoma and risk conditions. Hepatology 36:439-450

6. Han C, Leng J, Demetris AJ, Wu T (2004) Cyclooxygenase-2 promotes human cholangiocarcinoma growth: evidence for cyclooxygenase-2-independent mechanism in celecoxib-mediated induction of p21waf1/cip1 and p27kip1 and cell cycle arrest. Cancer Res 64:1369-1376

7. Han JA, Kim JI, Ongusaha PP, Hwang DH, Ballou LR, Mahale A, Aaronson SA, Lee SW (2002) P53-mediated induction of Cox-2 counteracts $\mathrm{p} 53$ - or genotoxic stress-induced apoptosis. EMBO J 21:5635-5644

8. Hawk E, Lubet R, Limburg P (1999) Chemoprevention in hereditary colorectal cancer syndromes. Cancer 86:2551-2563

9. Hayashi N, Yamamoto H, Hiraoka N, Dono K, Ito Y, Okami J, Kondo M, Nagano H, Umeshita K, Sakon M, Matsuura N, Nakamori S, Monden M (2001) Differential expression of cyclooxygenase-2 (COX-2) in human bile duct epithelial cells and bile duct neoplasm. Hepatology 34:638-650

10. Hou PC (1955) The pathology of Clonorchis sinensis infestation of the liver. J Pathol Bacteriol 70:53-64

11. Howe LR, Subbaramaiah K, Brown AM, Dannenberg AJ (2001) Cyclooxygenase-2: a target for the prevention and treatment of breast cancer. Endocr Relat Cancer 8:97-114

12. Javle MM, Yu J, Khoury $\mathrm{T}$, Chadha KC, Iyer RV, Foster J, Kuvshinoff BW, Gibbs JF, Geradts J, Black JD, Brattain MG (2006) Akt expression may predict favorable prognosis in cholangiocarcinoma. J Gastroenterol Hepatol 21:1744-1751

13. Kang YK, Kim WH, Lee HW, Lee HK, Kim YI (1999) Mutation of p53 and K-ras, and loss of heterozygosity of APC in intrahepatic cholangiocarcinoma. Lab Invest 79:477-483

14. Khan SA, Thomas HC, Toledano MB, Cox IJ, Taylor-Robinson SD (2005) p53 Mutations in human cholangiocarcinoma: a review. Liver Int 25:704-716
15. Khuder SA, Herial NA, Mutgi AB, Federman DJ (2005) Nonsteroidal antiinflammatory drug use and lung cancer: a metaanalysis. Chest 127:748-754

16. Kim HJ, Lee KT, Kim EK, Sohn TS, Heo JS, Choi SH, Choi DI, Lee JK, Paik SW, Rhee JC (2004) Expression of cyclooxygenase2 in cholangiocarcinoma: correlation with clinicopathological features and prognosis. J Gastroenterol Hepatol 19:582-588

17. Koga H, Sakisaka S, Ohishi M, Kawaguchi T, Taniguchi E, Sasatomi K, Harada M, Kusaba T, Tanaka M, Kimura R, Nakashima Y, Nakashima O, Kojiro M, Kurohiji T, Sata M (1999) Expression of cyclooxygenase-2 in human hepatocellular carcinoma: relevance to tumor dedifferentiation. Hepatology 29:688-696

18. Lai GH, Zhang Z, Sirica AE (2003) Celecoxib acts in a cyclooxygenase-2-independent manner and in synergy with emodin to suppress rat cholangiocarcinoma growth in vitro through a mechanism involving enhanced Akt inactivation and increased activation of caspases-9 and -3 . Mol Cancer Ther 2:265-271

19. Landis JR, Koch GG (1977) The measurement of observer agreement for categorical data. Biometrics 33:159-174

20. Levi S, Urbano-Ispizua A, Gill R, Thomas DM, Gilbertson J, Foster C, Marshall CJ (1991) Multiple K-ras codon 12 mutations in cholangiocarcinomas demonstrated with a sensitive polymerase chain reaction technique. Cancer Res 51:3497-3502

21. Liu CH, Chang SH, Narko K, Trifan OC, Wu MT, Smith E, Haudenschild C, Lane TF, Hla T (2001) Overexpression of cyclooxygenase-2 is sufficient to induce tumorigenesis in transgenic mice. J Biol Chem 276:18563-18569

22. Maier JA, Hla T, Maciag T (1990) Cyclooxygenase is an immediate-early gene induced by interleukin-1 in human endothelial cells. J Biol Chem 265:10805-10808

23. Mitchell JA, Belvisi MG, Akarasereenont P, Robbins RA, Kwon OJ, Croxtall J, Barnes PJ, Vane JR (1994) Induction of cyclooxygenase- 2 by cytokines in human pulmonary epithelial cells: regulation by dexamethasone. Br J Pharmacol 113:1008-1014

24. Patel T (2001) Increasing incidence and mortality of primary intrahepatic cholangiocarcinoma in the United States. Hepatology 33:1353-1357

25. Poligone B, Baldwin AS (2001) Positive and negative regulation of NF-kappaB by COX-2: roles of different prostaglandins. J Biol Chem 276:38658-38664

26. Sheng H, Shao J, Morrow JD, Beauchamp RD, DuBois RN (1998) Modulation of apoptosis and Bcl-2 expression by prostaglandin E2 in human colon cancer cells. Cancer Res 58:362-366

27. Sirica AE, Lai GH, Endo K, Zhang Z, Yoon BI (2002) Cyclooxygenase-2 and ERBB-2 in cholangiocarcinoma: potential therapeutic targets. Semin Liver Dis 22:303-313

28. Sobin LH, Wittekind C (2002) International union against cancer TNM classification of malignant tumours, 6th edn. Wiley, New-York

29. Watanabe M, Asaka M, Tanaka J, Kurosawa M, Kasai M, Miyazaki T (1994) Point mutation of K-ras gene codon 12 in biliary tract tumors. Gastroenterology 107:1147-1153

30. Wee A, Ludwig J, Coffey RJ Jr, LaRusso NF, Wiesner RH (1985) Hepatobiliary carcinoma associated with primary sclerosing cholangitis and chronic ulcerative colitis. Hum Pathol 16:719-726

31. Wendum D, Masliah J, Trugnan G, Flejou JF (2004) Cyclooxygenase- 2 and its role in colorectal cancer development. Virchows Arch 445:327-333

32. Wu T, Leng J, Han C, Demetris AJ (2004) The cyclooxygenase-2 inhibitor celecoxib blocks phosphorylation of Akt and induces apoptosis in human cholangiocarcinoma cells. Mol Cancer Ther 3:299-307

33. Zhang Z, Lai GH, Sirica AE (2004) Celecoxib-induced apoptosis in rat cholangiocarcinoma cells mediated by Akt inactivation and Bax translocation. Hepatology 39:1028-1037 